\title{
A "cadeia alimentar" no mercado da saúde: do disease mongering ao doctor shopping
}

\author{
The "food chain" in health market: from 'disease mongering' to 'doctor shopping' \\ La "cadena alimentaria" en el mercado de salud: desde 'disease mongering' hasta 'doctor shopping'
}

José Agostinho Santos. Unidade Local de Saúde Familiar Dunas. Lavra, Portugal. zeagostinho@hotmail.com (Autor correspondente)

\section{Resumo}

Nos anos mais recentes, têm surgido na literatura médica diferentes conceitos, tais como disease mongering, selling sickness e doctor shopping. Estes são três grandes fenômenos do atual mercado de saúde, que enfrenta o desafio de aumentar o lucro obtido intervindo em pessoas não doentes. Nesse sentido, têm se tornado notórias as inter-relações entre estes conceitos: 0 disease mongering alimenta um selling sickness, ao gerar o receio que impele a pessoa não doente à busca de uma tranquilização com procedimentos clínicos sem benefícios comprovados. A procura da prevenção ou do controle de alterações encontradas (que são normais, mas veiculadas como potencialmente patológicas) faz crescer um doctor shopping. Esta sequência estimuladora de um crescimento do consumo nada mais é do que uma autêntica cadeia alimentar. 0 médico de família e comunidade (MFC), enquanto advogado de defesa de seus pacientes, sentir-se-á envolvido pelo ímpeto de protegê-los de intervenções excessivas e inúteis, que iriam comprometer seu bem-estar biopsicossocial.

\section{Abstract}

In recent years, different concepts have emerged in the medical literature, such as disease mongering, selling sickness and doctor shopping. These are three major phenomena of the current healthcare market, which is facing the challenge of increasing its profit with healthy people. In this sense, the interrelationships between these concepts have made the news: disease mongering feeds selling sickness, generating fears that impel a healthy person to seek reassurance in clinical procedures with unproven benefits. This search for the prevention or control of casual body alterations (which are normal, but conveyed as possibly pathological) inflates doctor shopping. This enhancer sequence of consumption growth is nothing but an authentic food chain. General practitioners, as the defence lawyers of their patients, would feel taken by the need to protect them against excessive and unnecessary interventions that would compromise their biopsychosocial well-being.

\section{Resumen}

En los últimos años, han surgido en la literatura médica diferentes conceptos tales como disease mongering, selling sickness y doctor shopping. Se trata de tres fenómenos del actual mercado de salud que se enfrenta al reto de querer aumentar el beneficio económico, interviniendo en personas sanas. En este sentido, se han hecho visibles las relaciones entre estos conceptos: el disease mongering alimenta el selling sickness, generando un recelo que impulsa a la persona sana a buscar una tranquilidad en procedimientos clínicos que no han sido científicamente comprobados. La búsqueda de la prevención o del control de las alteraciones en la salud (que son normales pero han sido transmitidas como potencialmente patológicas) aumenta el doctor shopping. Sin embargo, esta secuencia que estimula el aumento del consumo no es más que una auténtica cadena alimentaria. El médico familiar y comunitario (MFC), como abogado defensor de sus pacientes, se sentirá envuelto por el ímpetu de protegerlos de intervenciones excesivas e innecesarias que pondrían en peligro su bienestar biopsicosocial.

\section{Palavras-chave:}

Qualidade de Vida

Setor de Assistência à Saúde

Mau Uso de Serviços de Saúde Medicalização

Prevenção Quaternária

\section{Keywords:}

Quality of Life Health Care Sector Health Services Misuse Medicalization Quaternary Prevention

\section{Palabras clave:} Calidad de Vida Sector de Atención de Salud Mal Uso de Servicios de Salud Medicalización Prevención Cuaternaria 
Nos últimos anos, têm surgido na literatura médica diferentes expressôes anglo-saxônicas correspondentes a fenômenos observados na dinâmica do mercado de saúde. Muitos clínicos conhecem bem estes conceitos, sendo capazes de reproduzir as suas definiçôes. Os demais talvez não estejam tão familiarizados com as definiçóes, mas convivem de perto com estes conceitos, com um maior ou menor insight.

Emergem então conceitos denominados disease mongering, selling sickness e doctor shopping. Estes são três grandes fenômenos deste mercado notoriamente lucrativo e que enfrenta agora o desafio de expansão exponencial a níveis nunca antes alcançados, segundo um simples princípio: o lucro obtido com as pessoas com patologias já é considerável, porém poderá ser talvez ainda maior se for abarcado o grupo das pessoas náo doentes. E tudo acontece, paradoxalmente ou não, neste momento em que emergem correntes que apelam a uma medicina centrada na pessoa (pessoa enquanto ser humano único, bem mais do que um doente) em vez de uma medicina centrada no doente ou na doença.

$\mathrm{O}$ disease mongering tem uma tradução portuguesa grosseira para "comercializar a doença" e consiste neste fenômeno de fomentaçáo de uma preocupaçáo generalizada, indiscriminada e inadequada entre as pessoas da populaçáo geral, náo doentes, sobre o eventual surgimento de uma doença que coloque em risco suas vidas ou sua qualidade de vida, elevando a necessidade de atitudes (lucrativas para terceiros) para reduzir esse risco. Estimulada por entidades com fins lucrativos, a intensa propaganda de indução desse receio consegue atingir também os médicos por meio de estratégias bem montadas (envolvendo, quiçá, opinióes de outros profissionais de saúde, chamados de opinion liders ou formadores de opiniáo) que estreitam os limites do normal e alargam o que passa a ser considerado patológico, incentivando a medicalizaçáo. ${ }^{1,2} \mathrm{Na}$ realidade, este estreitamento de limites nada mais é do que o selling sickness (venda da doença e do adoecimento) e consiste precisamente neste processo que envolve dois passos essenciais: o apontamento de alteraçôes expectáveis e previsíveis que surgem de uma população que é mutável, diversa e variada (não sendo sempre imutável e padronizada) e posterior hipervalorização dessas variaçóes como lesóes patológicas e com necessidade de atuação (lucrativa para terceiros) para seu controle ou reversão. ${ }^{2}$

Finalmente, o doctor shopping constitui este circuito de procura de múltiplas consultas médicas (frequentemente da mesma especialidade médica), retentora de múltiplas "segundas opiniôes", de múltiplas prescrições farmacológicas e de realização de incontáveis exames complementares. Tradicionalmente, o doctor shopping era exercido por pacientes que procuravam as prescriçóes extra de alguns fármacos (nomeadamente opiáceos), omitindo aos seus médicos as consultas e os percursos anteriores, ${ }^{3}$ porém tendo a saúde se tornado um bem de consumo, parece que este conceito necessita ser ampliado a todo um cenário em que as pessoas são induzidas a pensar que possuem problemas de saúde ou, se já os tem, a pensar que tais problemas são mais sérios e que elas próprias são mais vulneráveis do que de fato são. Isso promove a procura por inúmeras consultas (a maioria em instituiçôes de saúde privadas), buscando uma tranquilização não tanto com as prescriçôes, mas sim com diversas abordagens. ${ }^{4}$ Entre as múltiplas abordagens, desenrolam-se a realização e a interpretação de vários exames complementares que, por sua vez, sinalizam alteraçóes inespecíficas ou falsos positivos. Esse processo resulta em outra sequência de meios complementares e de consultas específicas de outras áreas, algo que, retroativamente, estimula o gatilho de início desse trajeto (também lucrativo para terceiros). ${ }^{5}$

Procedendo assim à identificação destes fenômenos de forma isolada, rotulando-os com esta conjugação de duas palavras que em tudo se assemelha à identificação de uma espécie de ser vivo (apenas diferindo no ponto em que não é usado o latim), têm-se tornado notórias as inter-relaçóes entre estes conceitos, cada um deles como se fosse uma espécie de acontecimento tão vivo quão atual. De fato, o disease mongering alimenta um selling sickness, ao gerar o receio que impele a pessoa não doente à busca de uma tranquilização com procedimentos clínicos sem benefícios comprovados. Identificadas alteraçōes sem valor concreto, estas são embrulhadas com papel ansiogênico de dissimulada importância, vendendo-se o adoecimento (vivência de doença). A procura da prevenção ou do controle de tais alteraçóes (normais, mas veiculadas como potencialmente patológicas) faz crescer um doctor shopping. Ora, esta sequência estimuladora de um crescimento nada mais é do que uma autêntica cadeia alimentar, tal como as cadeias observadas no âmbito da biologia.

Se fosse permitida a aplicação de uma linguagem zoológica, o disease mongering e o selling sickness seriam produtores e o doctor shopping seria o consumidor. Nesta mesma analogia, os biólogos seriam certamente os especialistas em Medicina de Família e Comunidade (MFC). Na verdade, alguns dos nomes mais reconhecidos por suas contribuiçôes na descrição destes fenômenos são Marc Jamoulle, Juan Gérvas e Iona Heath, todos eles médicos de família. Entender-se-á facilmente que tal não ocorre por acaso, sobretudo se for relembrado que a clara maioria das pessoas sem doença é observada e acompanhada pelos seus médicos de família. São estas pessoas as mesmas sequestradas pelo disease mongering e pelo selling sickness, assaltadas pelos receios e mitos e que tantas vezes regressam de forma intranquila ao consultório do seu médico de família. 
Serão, portanto, os médicos de família estes biólogos que observarão de forma mais direta estas movimentaçôes ativas, motivados a descrevê-las. Porém, mais do que descrever, o médico de família, enquanto dotado de estatuto reconhecido pela WONCA como advogado de defesa do seu paciente, ${ }^{6}$ sentir-se-á envolvido pelo ímpeto de salvaguardar a integridade da pessoa e de a proteger contra intervençôes tão excessivas quanto inúteis que iriam comprometer o seu bem-estar biopsicossocial. Esse é o exercício da prevenção quaternária, estratégia baseada na evidência científica e que visa estabelecer o equilíbrio neste ecossistema, impedindo o comprometimento dos cuidados integrados à pessoa num âmbito holístico e atendendo a todas as dimensóes dessa pessoa. Fazem parte deste ecossistema tanto médicos como pacientes e, por isso, desequilibrá-lo significa elevar o risco clínico.

Será, talvez, absolutamente fundamental integrar estes conceitos de forma contundente nos cursos de graduação e pós-graduação de MFC, assim como de outras especialidades médicas, em disciplinas como a Medicina Preventiva ou em cursos de medicina baseada em evidência. Ademais, será igualmente importante discutir e realçar de forma precoce na graduação médica a dominância atual da medicalização da história natural do indivíduo desde o seu nascimento e dos comportamentos sociais. ${ }^{7}$ A medicalização consiste em outro fenômeno que, embora convergente e sinérgico, transcende o disease mongering, selling sickness ou doctor shopping, atingindo a própria produção do conhecimento médico. Isto é especialmente notado para as especialidades médicas focais, mas poderá afetar inclusive, sobremaneira e inevitavelmente, o saber da própria Medicina de Família e Comunidade, tornando mais difícil a isenção e a resistência aos três fenômenos citados. É reconhecido que os próprios profissionais médicos têm historicamente participado desse movimento medicalizador, o que impóe um desafio ético e epistemológico ao médico de família e comunidade: reverter esse papel de medicalização ativa, destacando a sua atividade profissional de qualquer outra especialidade. Exercer a prevenção quaternária é, portanto, mais do que uma estratégia. É uma atitude clínica tão obrigatória para a construçáo de uma identidade enquanto médico de família, quanto complexa nesta cultura geral das pessoas que, sendo vítimas deste processo mais amplo de medicalização da vida, vêm aumentar a sua insegurança e a sua crença na tecnologia diagnóstica, terapêutica e preventiva, dificultando a aquisição do equilíbrio no citado ecossistema.

Finalmente, o autor sugere que poderia haver medidas governamentais que apoiassem inequivocamente uma massificação de medidas 'quaternariamente preventivas' que vão muito além das diretrizes clínicas. Especificamente para a MFC, seriam medidas que preservassem a sua identidade própria e que eliminassem alguns indicadores de avaliação de desempenho profissional com raiz meramente quantitativa. Em um mercado de saúde tão lucrativo e certamente poderoso, tal massificação constituirá um verdadeiro desafio.

\section{Referências}

1. Melo M. A promoção da doença. A quem interessa? Rev Port Clin Geral. 2007;23:361-4.

2. Moynihan R, Heath I, Henry D. Selling sickness: the pharmaceutical industry and disease mongering. BMJ. 2002;324:886-91. PMid:11950740 PMCid:PMC1122833. http://dx.doi.org/10.1136/bmj.324.7342.886

3. McDonald DC, Carlson KE. Estimating the prevalence of opioid diversion by "Doctor Shoppers" in the United States. PLoS One. 2013;8(7):e69241 PMid:23874923 PMCid:PMC3714248. http://dx.doi.org/10.1371/journal.pone.0069241

4. Sansone RA, Sansone LA. Doctor Shopping: a phenomenon of many themes. Innov Clin Neurosci. 2012;9(11-12):42-6. Pmid:23346518. Disponível em: http://innovationscns.com/doctor-shopping-a-phenomenon-of-many-themes/.

5. Melo M. A prevenção quaternária contra os excessos da Medicina. Rev Port Clin Geral. 2007;23(3):289-93. Disponível em: http://www.rpmgf.pt/ojs/index.php?journal=rpmgf\&page=article\&op=view\&path\%5B\%5D=10361.

6. World Organization of Family Doctors (Wonca Europa). A definição europeia de Medicina Geral e Familiar(Clínica Geral / Medicina Familiar). Portugal: Wonca Europa; 2002. p. 6-14. Disponível em: http://www.woncaeurope.org/content/portugal-defini\%C3\%A7\%C3\%A3o-europeia-demedicina-geral-e-familiar-cl\%C3\%ADnica-geral-medicina-familiar.

7. Gérvas J, Pérez Fernández M. Uso y abuso del poder médico para definir enfermedad y factor de riesgo, en relación con la prevención cuaternaria. Gac Sanit. 2006;20(Suppl 3):66-71. PMid:17433203. http://dx.doi.org/10.1157/13101092 